\title{
THE INFLUENCE OF STREPTOMYCIN ON THE INCIDENCE OF PLEURAL EFFUSION COMPLICATING THE DIVISION OF ADHESIONS
}

\author{
BY \\ D. C. BEATTY AND A. WIENER \\ From the London Hospital
}

(RECEIVED FOR PUBLICATION JUNE 3, 1952)

It is recognized that the development of an effusion following the division of adhesions in an artificial pneumothorax is a common complication and that in an appreciable proportion of the cases it leads to loss of the artificial pneumothorax from obliterative pleurisy. It predisposes to tuberculous or mixed empyema, and through the development of pleural fibrosis and thickening the lung may subsequently not expand. Fluid covering the diaphragm is generally considered to be significant and an indication for aspiration. Smaller collections of fluid usually resolve if left alone.

The incidence of pleural effusion after the division of adhesions has varied greatly in the different series published in the literature. Goorwitch (1948), reviewing cases published in the English and American literature from 1943 to January, 1947, stated that in the various series a large serous effusion occurred in $3 \%$ to $23 \%$, a small serous effusion in $5.5 \%$ to $40 \%$, and a tuberculous empyema in from 0 to $5.5 \%$. Watt (1947), publishing the largest series in the English literature, quoted an effusion rate of $32 \%$ occurring within two weeks of operation in a series of 820. More recent series have tended to show a rather lower rate, Wollaston (1947), for example, quoting an incidence of $20 \%$, Goorwitch (1948) $5 \%$, Strandgaard (1950) $11 \%$, and Bernhardt (1951) $9.8 \%$.

There are many reasons for this variation; the selection of cases for the induction of an artificial pneumothorax, the timing of both induction and the subsequent section of adhesions, and the type of disease being treated are the most important factors. Where a large number of adhesions need to be cut, and especially if these are not all divisible, effusions are more likely to occur. The presence of an effusion at any time before operation predisposes to the development of one after it (Kunstler, 1947 ; Strandgaard, 1950).
The length of the post-operative period during which the division of adhesions may be regarded as contributory to the development of complications varies in the published series. Goorwitch (1943 and 1948) states that the majority of complications occur within the first month after operation. Day, Chapman, and O'Brien (1948) take a two months' period. They state that in only $16.8 \%$ of cases developing fluid after that time had there been no evidence of a preceding effusion. In Watt's (1947) series of 820 adhesion sections there were $293(36 \%)$ effusions within two weeks, 23 $(2.8 \%)$ in the period three to eight weeks after operation, and only $60(7 \%)$ developed later than eight weeks. It appears therefore that the great majority of post-operative effusions occur within a period of eight weeks, and it was decided for the purpose of this review to take this as an arbitary period. It is doubtful if later effusions can be blamed directly on the operation.

When streptomycin became available it was used at first for the treatment of acute exudative disease. Artificial pneumothorax was induced when it was deemed that the toxaemia had abated and the disease was under control. It seemed logical to continue the streptomycin to cover the section of adhesions, and we had the impression that post-operative effusions occurred less often in these cases than in those which had not been given streptomycin as the disease was not sufficiently extensive or acute. It was already known (Levin, Carr, and Heilman, 1948) that streptomycin appeared in bacteriostatic concentrations in pleural fluid when given by the intramuscular route.

In an attempt to prove this theory, it was planned to carry out a series of adhesion sections under cover of streptomycin and to compare this series with a similar one in which streptomycin was not used. The original aim was to start the 
streptomycin 48 hours before thoracoscopy in a dose of $1 \mathrm{~g}$. intramuscularly daily with para-aminosalicylic acid (P.A.S.) by mouth in doses of 16 to $20 \mathrm{~g}$. a day in divided doses and to continue for three weeks. It was thought that this would ensure an adequate concentration of streptomycin reaching the pleura during the immediate danger period following the operation without continuing it long enough to run the risk of resistance developing.

When streptomycin was being used in preparation for collapse therapy it was either continued to cover the induction and the thoracoscopy, or started again after an interval to cover the thoracoscopy. The induction was not always covered.

Because of the number of factors which influence the complication rate in dividing adhesions, it was thought desirable to provide a control series against which the effect of streptomycin could be measured. The ideal would be to give streptomycin as a cover for each alternate operation. It soon became obvious that this was impossible, as the benefits of streptomycin in the acute case as a preparation for collapse therapy were such that it would not have been justifiable to withhold it. As the trial proceeded it was found that the results in cases treated with streptomycin were sufficiently encouraging to warrant using it as a cover for all adhesion sections. So it was decided to compare the results obtained in those cases in which streptomycin was used with those in which it was not. The majority of cases without streptomycin cover, therefore, fell into the first period of this study.

In this paper the complication rate following adhesion section in those cases receiving streptomycin as a cover, and in many instances also as a preparation for collapse therapy, is compared with that obtained in a series in which no kind of chemotherapy was used at any time. It is emphasized, however, that this latter series does not constitute an actual control series.

All cases between April, 1948, and April, 1951, have been included except where it was found at thoracoscopy that there was no adhesion. All cases were under the care of the same two physicians, and all operations were performed by the same surgeon. From April, 1950, onwards all cases received streptomycin as a cover for the operation. The results are given in Table I. Four cases in each group had bilateral artificial pneumothorax. The findings in each group refer to a period of eight weeks after section. No
TABLE I

RESULTS IN 115 CASES OF ADHESION SECTION WITH AND WITHOUT STREPTOMYCIN

\begin{tabular}{|c|c|c|c|c|c|c|}
\hline Total & $\begin{array}{l}\text { Artificial } \\
\text { Pneumo- } \\
\text { thoraces }\end{array}$ & $\begin{array}{l}\text { Adhesion } \\
\text { Sections }\end{array}$ & Effusion & $\begin{array}{c}\text { Lobar } \\
\text { Collapse }\end{array}$ & $\begin{array}{l}\text { Cavity } \\
\text { not } \\
\text { Closed }\end{array}$ & Spread \\
\hline \multicolumn{7}{|c|}{ Strcptomycin group } \\
\hline 54 & 57 & 69 & $\begin{array}{c}1 \\
\text { (culture } \\
\text { negative) }\end{array}$ & 4 & 2 & 0 \\
\hline \multicolumn{7}{|c|}{ Non-streptomycin group } \\
\hline & 65 & & $\begin{array}{c}16 \\
(7 \text { culture for } \\
M . \text { tuber- } \\
\text { culosis) } \\
\text { (1 true } \\
\text { empyema) }\end{array}$ & 11 & 6 & 3 \\
\hline
\end{tabular}

pyogenic empyema occurred and penicillin was not used.

It will be seen that effusions requiring aspiration, i.e., covering the diaphragm or more, occurred in only one of the patients receiving streptomycin (1.4\% of adhesion sections) and that this was negative on culture for $M$. tuberculosis, whereas $16(21.6 \%)$ of those in the group who did not receive streptomycin developed effusions, seven of these giving a positive culture for $M$. tuberculosis. The only case of true empyema occurred in this group. The figures for the development of an effusion are significantly different $\left(\chi^{2}=13.6, \mathrm{n}=1, \mathrm{P}<0.001\right)$.

The figures as regards lobar collapse are not by themselves statistically significant, but if combined with those for the development of an effusion they become so $\left(\chi^{2}=17.0, \mathrm{n}=1, \mathrm{P}<0.001\right)$. It is of interest to note that in the group which did not receive streptomycin there were more cases in which the cavity failed to close, and that the only three cases which developed a spread were in this group.

A further analysis of the two groups indicates that they are roughly comparable (Table II). It 0

TABLE II
COMPARISON OF GROUPS ACCORDING TO EXTENT OF
DISEASE

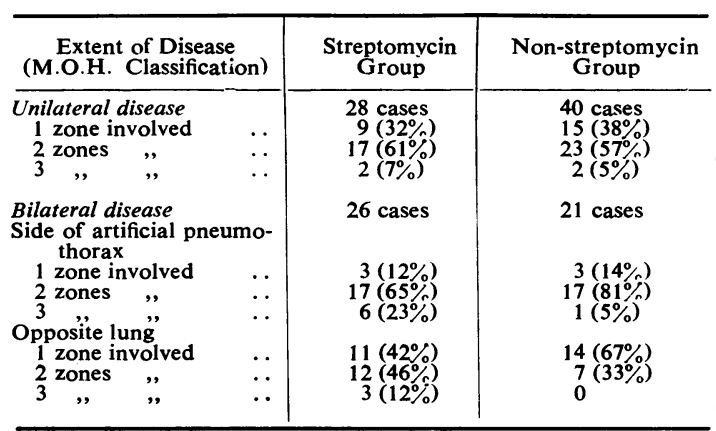


will be seen that in the streptomycin group $48 \%$ of cases have bilateral disease, whereas in the nonstreptomycin group the proportion is $35 \%$. When the cases are further subdivided according to the extent of lung involved on each side it is apparent that all three zones were involved in two cases in each group in those with unilateral disease, whereas in those with bilateral disease all three zones on the side of the artificial pneumothorax were involved in six cases in the streptomycin group but in only one in the non-streptomycin group.

TABLE III

SIGNIFICANCE OF PRESENCE OF CAVITIES OR POSITIVE SPUTUM BEFORE AND AFTER ADHESION SECTION

\begin{tabular}{c|c|c|c|c}
\hline & \multicolumn{2}{|c|}{$\begin{array}{c}\text { Before } \\
\text { Adhesion Section }\end{array}$} & \multicolumn{2}{|c}{$\begin{array}{c}\text { After } \\
\text { Adhesion Section }\end{array}$} \\
$\begin{array}{c}\text { Streptomycin group } \\
\text { (54 cases) } \\
\text { Unilateral and } \\
\text { bilateral disease }\end{array}$ & $\begin{array}{c}\text { Sputum+ }+ \\
39(72 \%)\end{array}$ & $\begin{array}{c}\text { Cavity } \\
44(82 \%)\end{array}$ & $\begin{array}{c}\text { Sputum+ } \\
9(17 \%)\end{array}$ & $\begin{array}{c}\text { Cavity } \\
8(16 \%)\end{array}$ \\
$\begin{array}{c}\text { Non-streptomycin } \\
\text { group (61 cases) } \\
\text { Uilateral and } \\
\text { bilateral disease }\end{array}$ & $49(80 \%)$ & $45(74 \%)$ & $17(28 \%)$ & $10(16 \%)$ \\
\hline
\end{tabular}

Table III shows that there is no great difference between the two groups as to the presence of a cavity and of a positive sputum before and after section of adhesions.

TABLE IV

NUMBER OF ADHESIONS SEEN AT THORACOSCOPY

\begin{tabular}{|c|c|c|c|}
\hline & & $\begin{array}{c}\text { Before } \\
\text { Section }\end{array}$ & $\begin{array}{l}\text { Persisting } \\
\text { Adhesions }\end{array}$ \\
\hline $\begin{array}{c}\text { Streptomycin grou } \\
\text { (57 artificial pne } \\
\text { Many } \\
\text { Moderate } \\
\text { One } \quad . .\end{array}$ & 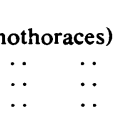 & $\begin{array}{r}26(46 \%) \\
22(38 \%) \\
9(16 \%)\end{array}$ & $\underset{0}{11}(2 \%)$ \\
\hline $\begin{array}{c}\text { Non-streptomycin } \\
\text { (65 artificial pne } \\
\text { Many } \\
\text { Moderate } \\
\text { One }\end{array}$ & 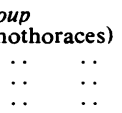 & $\begin{array}{l}32(49 \%) \\
20(31 \%) \\
13(20 \%)\end{array}$ & $\begin{array}{c}1(2 \%) \\
25(41 \%) \\
0\end{array}$ \\
\hline
\end{tabular}

In Table IV the number of adhesions found at thoracoscopy have been roughly divided into three grades in the two groups, and a note is made of the number of cases in each group in which it was not possible to divide all the adhesions.

The period of bed-rest preceding operation was not considered in detail, as it was not always possible to discover this from the notes on those patients who had been in bed at home. A recent paper by Scadding, Nicholson, and Hoyle (1951) suggests that this may not be of great importance.
It is considered that the groups are roughly comparable and that, if anything, the more severe cases fall into the streptomycin group. It was not practicable to assess accurately the acuteness of the disease in the two groups, but, as previously explained, streptomycin tended to be used in those cases with acute exudative disease.

If it were true that the cases treated with streptomycin were on the whole more severe than those not so treated, and that streptomycin was effective in reducing the incidence of post-operative effusions, it would be expected that the cases submitted to thoracoscopy before the advent of streptomycin would show a greater incidence of complications than either of the groups discussed above. It was therefore thought that it might be of interest to examine the 50 cases treated in the same hospital immediately preceding those described in this paper. In this group 50\% developed an effusion and $28 \%$ developed lobar collapse (Table V).

TABLE V

CASES TREATED PRECEDING USE OF STREPTOMYCIN (1947 AND EARLY 1948)

\begin{tabular}{c|c|c}
\hline Cases & Fluid & Lobar Collapse \\
\hline 50 & $\begin{array}{c}25 \\
\text { (14 culture-positive })\end{array}$ & 14 \\
\hline
\end{tabular}

The only reference in the literature to the use of streptomycin as a cover for artificial pneumothorax which we have been able to discover is the series reported by Mattei, Mayer, Tristani, Barbe, Balozet, and Mattei (1951). They stated that in those cases where there was extensive pleural adhesion the artificial pneumothorax could be maintained for long periods without an effusion developing when streptomycin was used as a cover and that ultimately the adhesions became divisible. He reported only five effusions in 190 cases.

We believe, therefore, that streptomycin is of value in preventing the complication of pleural effusion following division of adhesions, possibly also other complications such as collapse and spread. It is suggested that all operations to divide adhesions should be covered by a course of streptomycin.

\section{SUMMARY}

Pleural effusion is one of the commonest complications following the division of adhesions in artificial pneumothorax and often leads to its abandonment.

A series of 54 cases given streptomycin as cover for adhesion section has been compared with a series of 61 not given streptomycin. 
The incidence of pleural effusion in the streptomycin group was $1.4 \%$; in the non-streptomycin group it was $21.4 \%$.

It is recommended that all patients undergoing adhesion section be covered by a course of streptomycin.

We should like to thank Dr. Kenneth Perry, Dr. Lloyd Rusby, and Mr. Vernon Thompson, under whose care these patients were, for their help and encouragement. Our thanks are also due to Mr. Vobes for his statistical help.

\section{REFERENCES}

Bernhardt, J. (1951). Dtsch. GesundhWes., 6, 445.

Day, J. C., Chapman, P. T., and O'Brien, E. J. (1948). J. thorac. Surg., 17, 537.

Goorwitch, J. (1943). Amer. Rev. Tuberc., 48, 205

(1948). Ibid., 58, 42.

Kunstier, W. E. (1947). J. thorac Surg., 16, 353

Levin, L., Carr, D. T., and Heilman, F. R. (1948). Amer. Rev. Tuberc., 58, 531 .

Mattei, C., Mayer, M., Tristani, M., Barbe, A., Balozet, P., and Mattei, M. (1951). Presse méd., 59, 558.

Scadding, F., Nicholson, H., and Hoyle, C. (1951). Quart. J. Med. $20,313$.

Strandgaard, E. (1950). Acta tuberc. scand., 24, 259

Watt, J. (1947). Tubercle, Lond., 28, 158.

Wollaston, F. L. (1947). Lancet, 2, 424. 